\title{
Lipid nanocapsules for behavioural testing in aquatic toxicology: time-response of Eurytemora affinis to environmental concentrations of PAHs and PCB
}

\author{
François-Gaël Michalec ${ }^{\mathrm{a}, *}$, Markus Holzner $^{\mathrm{a}}$, Anissa Souissi ${ }^{\mathrm{b}}$, Stefka Stancheva ${ }^{\mathrm{c}}$, \\ Alexandre Barras ${ }^{\mathrm{c}}$, Rabah Boukherroub ${ }^{\mathrm{c}}$, Sami Souissi ${ }^{\mathrm{b}}$ \\ ${ }^{a}$ Institute of Environmental Engineering, ETH Zurich, Stefano-Franscini-Platz 5, 8093 Zurich, Switzerland \\ ${ }^{b}$ Univ. Lille, CNRS, UMR 8187, LOG, Laboratoire d'Océanologie et de Géosciences, F 59000 Lille, France \\ ${ }^{c}$ Univ. Lille, CNRS, UMR 8520, IEMN, Institut d'Electronique, de Microélectronique et de \\ Nanotechnologie, F 59000 Lille, France
}

\begin{abstract}
The increasing interest for behavioural investigations in aquatic toxicology has heightened the need for developing tools that allow realistic exposure conditions and provide robust quantitative data. Calanoid copepods dominate the zooplankton community in marine and brackish environments. These small organisms have emerged as attractive models because of the sensitivity of their behaviour to important environmental parameters and the significance of self-induced motion in their ecology. Estuarine copepods are particularly relevant in this context because of their incessant exposure to high levels of pollution. We used lipid nanocapsules to deliver sub-lethal concentrations of PAHs (pyrene, phenanthrene and fluoranthene) and PCB 153 into the digestive track of males and females Eurytemora affinis. This novel approach enabled us to achieve both contact and trophic exposure without using phytoplankton, and to expose copepods to small hydrophobic molecules without using organic solvent. We reconstructed the motion of many copepods swimming simultaneously by means of three-dimensional particle tracking velocimetry. We quantified the combined effects of contact and trophic toxicity by comparing the kinematic and diffusive properties of their motion immediately and after $3 \mathrm{~h}$ and $24 \mathrm{~h}$ of exposure. Despite the lack of toxicity of their excipients, both empty and loaded capsules increased swimming activity
\end{abstract}

\footnotetext{
${ }^{*}$ Corresponding author

Email address: michalec@ifu.baug.ethz.ch (François-Gaël Michalec)
}

Preprint submitted to Aquatic Toxicology

August 20, 2015 
and velocity immediately after exposure. Laser microscopy imaging shows adhesion of nanocapsules on the exoskeleton of the animals, suggesting contact toxicity. The behavioural response resembles an escape reaction allowing copepods to escape stressful conditions. The contact toxicity of empty capsules and pollutants appeared to be additive and nanocapsules loaded with PCB caused the greatest effects. We observed a progressive accumulation of capsules in the digestive track of the animals after $3 \mathrm{~h}$ and $24 \mathrm{~h}$ of exposure, which suggests an increasing contribution of systemic toxicity. Nanocapsules filled with PAHs caused a smaller response compared to empty capsules, which we attribute to the narcotic properties of these toxicants. The sharp decrease in velocity after $24 \mathrm{~h}$ of exposure to capsules loaded with PCB suggests physiological incapacitation following systemic toxicity. Clear differences are visible between genders in their response to empty and loaded capsules, for all exposure durations. Females appear to be less sensitive than males, suggesting different tolerance to stress conditions. Our results confirm the feasibility of using lipid nanocapsules to identify pollutantinduced behavioural alteration in the plankton. They also add new insights into the contact and systemic toxicity of common pollutants. We expect that our results will assist and evoke further research to develop suitable nanocarrier systems for behavioural testing.

Keywords:

calanoid copepod, swimming behaviour, Eurytemora affinis, waterborne pollution, lipid nanocapsule, particle tracking velocimetry

\section{Introduction}

Copepods form the largest part of the zooplankton in marine and brackish environments. They are considered as promising model organisms because of their short generation time, ease of culturing in the laboratory and major ecological importance. Using copepods as test models, considerable effort has been directed in identifying appropriate molecular and cellular biomarkers and in understanding the mechanisms of toxic action at these two levels of biological organisation (Raisuddin et al., 2007; Xuereb et al., 2012). Together with conventional mortality assays and assessment of 
reproductive and developmental impairments (Guo et al., 2012; Lesueur et al., 2015), these tests provide comparative and standardised results that directly relate to the health and fitness of an organism. On the other hand, they provide little information on the impairment of behavioural processes that often occur at extremely low concentrations of pollutants (Ward et al., 2008; Henry et al., 2012). Individual behaviour underlines almost all aspects of ecological interactions and links sub-organism levels to higher ecological levels such as population organisation. Because behavioural studies are relatively fast and behavioural endpoints are generally more sensitive than those assessing development or reproduction (Melvin and Wilson, 2013), examining changes in behaviour has been in recent years an increasingly popular approach to appreciate anthropogenic disturbances in aquatic organisms (Clotfelter et al., 2004; Zala and Penn, 2004). However, in the field of zooplankton toxicology, behavioural studies remain disproportionately biased toward studying freshwater cladoceran (Duquesne and Küster, 2010; Chevalier et al., 2015; Zein et al., 2015). Despite the increasing demand for using ecologically-relevant species for pollution monitoring, little is known about copepods from marine or brackish environments.

The interest of using calanoid copepods as model organisms in behavioural assays takes on full significance when considering the importance of swimming behaviour in their ecology. These small organisms rely on behaviour to explore their environment and to interact with other zooplankters. Small-scale motion on the order of a few centimetres contributes greatly to their fitness (Visser, 2007; Kiørboe, 2008; Bianco et al., 2014). The kinematic and geometrical properties of their trajectories are sensitive to a variety of natural parameters (Michalec et al., 2012; Moison et al., 2012; Sabia et al., 2014) and the feasibility and ecological significance of using copepod behaviour in environmental monitoring has been recognised in recent publications (Michalec et al., 2013a,b). These studies motivate further research to expand our knowledge on the behavioural toxicity of various classes of pollutants, and to develop innovative procedures for behavioural analysis.

Two recurrent problems in behavioural toxicology are the use of carrier solvents and the route of exposure. Carrier solvents are needed to assess substances that are sparingly soluble and there is often no other practical alternative for the testing of rela- 
tively hydrophobic substances (Hutchinson et al., 2006). However, they can have confounding effects that have been recognized both in chronic (Hutchinson et al., 2006) and in behavioural assessment of toxicity (Michalec et al., 2013b). Because copepods have a relatively impermeable chitinous exoskeleton, internal concentrations of toxicants after direct uptake are generally considerably less than background concentrations (Chang and Reinfelder, 2002; Magnusson et al., 2007). Toxicants from the dissolved phase deposit primarily on external surfaces and in calanoid copepods as in other planktonic crustaceans, they often result in typical escape reactions that are believed to result from damage or irritation of chemoreceptor cells (Lopes et al., 2004; Blinova and Cherkashin, 2012). In the environment, however, copepods are exposed to pollutants not only through direct contact but also via trophic exposure. Toxicants can be taken up through the cuticle and through the digestive tract after ingestion of contaminated phytoplankton. Trophic transfer generally leads to greater effects (Fisher and Hook, 2002; Rozon-Ramilo et al., 2011) because toxicants deposit in internal tissues and strongly perturb physiological functions (Escher and Hermens, 2002). Consequently, there is a call for biologists to consider not only contact toxicity, but also the trophic transfer of pollutants in order to better understand the relative importance of water and diet as routes of exposure causing behavioural impairments.

Because phytoplankton is the primary diet for calanoid copepods, unicellular algae seem to be the most suitable choice to deliver toxicants systemically (Jarvis et al., 2013; Almeda et al., 2014b). However, in behavioural assays, using contaminated phytoplankton is considered impractical. Both the internal concentration of toxicants in the algae and their assimilation efficiency in copepods have been found to vary with the pollutant and species of algae considered (Xu et al., 2001; Wang and Wang, 2005; Magnusson et al., 2007). They also depend on the concentration of nutrients (Wang and Dei, 2001; Lynn et al., 2007) and on non-trivial kinetics of uptake and desorption (Koelmans, 2014). Moreover, the swimming behaviour of copepods is affected by the presence of phytoplankton with species-dependent effects (Saiz, 1994; van Duren and Videler, 1995; Sabia et al., 2014) and both the grazing rate of copepods and their grazing selectivity depend on the species of copepods and algae considered (Garrido et al., 2013). In this context, objectives must be geared toward the development of a carrier 
71 system that delivers hydrophobic toxicants to the digestive track without reliance on phytoplankton or solvent. This carrier system must target the digestive system independently of the grazing selectivity of the copepod and remain stable in brackish or sea water over the duration of the experiment. One strategy relies on the association of toxicants with nanocarriers that protect the encapsulated substance and transport it across the epithelial surface of the digestive track. The use of nano-sized particles as delivery systems for poorly water-soluble drugs has recently attracted considerable pharmaceutical interest (Bunjes, 2010) but has never been implemented in aquatic toxicology. We have recently demonstrated that lipid nanocapsules fulfill these requirements: they are not toxic to copepods, stable in seawater and very efficient at encapsulating hydrophobic toxicants (Stancheva et al., 2015).

We focus in this study on polycyclic aromatic hydrocarbons (PAHs) and polychlorinated biphenyls (PCBs), two widespread organic pollutants that tend to remain in the environment for extended periods of time. Polycyclic aromatic hydrocarbons accumulate in copepods (Lotufo, 1998; Carls et al., 2006; Cailleaud et al., 2007a; Berrojalbiz et al., 2009) and affect their development, survival and reproduction (Barata et al., 2005; Bellas and Thor, 2007; Saiz et al., 2009). Because copepods ingest dispersed oil droplets, renewed attention has been focused on the ingestion and toxic effects of PAHs on the zooplankton community (Almeda et al., 2014a). Polychlorinated biphenyls are highly lipophilic compounds that accumulate in aquatic organisms including copepods (Cailleaud et al., 2007a) where they exhibit a broad range of toxicological effects on physiological functions (McFarland and Clarke, 1989). We selected the estuarine calanoid copepod Eurytemora affinis (Poppe 1880) as a model species because of its large distribution area which includes most temperate estuaries and its high importance in the trophic food web (Devreker et al., 2008). This species is associated to the maximum turbidity zone where it finds abundant food (Tackx et al., 2003) but encounters high levels of pollution due to the trapping of particulate contaminants and sediment re-suspension (Cailleaud et al., 2009b; Lesueur et al., 2015). It accumulates environmental contaminants (Cailleaud et al., 2007b, 2009a, 2011a) and has over the years become a relevant ecological and ecotoxicological bioindicator (Forget-Leray et al., 2005; Lesueur et al., 2013; Kwok et al., 2015). 
132 et al., 2015).

Automated tracking of the collective behaviour of small organisms in three dimensions allows the reconstruction of a large number of trajectories and ensures a reliable database for the analysis of their motion. Recent developments in tracking procedures have provided biologists with unprecedented quantities of trajectories and have allowed the description and understanding of behaviour at scales previously not possible (Ardekani et al., 2013; Attanasi et al., 2015). Despite the growing interest in using zooplankton behaviour as an integrated measure of aquatic contamination, quantitative characterization of their three-dimensional trajectories remains uncommon. This is primarily because there is no standard technique to recover the position information of a large number of animals moving simultaneously. Three-dimensional particle tracking velocimetry is a flow measurement technique originally developed to study turbulent flows and recently applied to study swarming midges (Kelley and Ouellette, 2013) and copepods swimming in turbulence (Michalec et al., 2015). It allows the automatic processing of long sequences of stereoscopic images and the reconstruction of the three-dimensional positions and trajectories of a large number of particles.

This research was conducted to test for the feasibility of using lipid nanocapsules as carrier of hydrophobic molecules in behavioural toxicology, and to test for the extent of behavioural effects induced by both contact and trophic-like exposure. We reconstructed the motion of adult $E$. affinis swimming freely in clean water, in the presence of empty nanocapsules and during exposure to nanocapsules filled with PCB 153 and with a mixture of PAHs. We hypothesized that (i) copepods would not react to the presence of empty nanocapsules (ii) copepods would react to the initial stage of the exposure by displaying hyperactivity due to contact toxicity and (iii) longer exposure would result in lower swimming activity that may indicate systemic toxicity. The first hypothesis is based on the non-toxicity of lipid nanocapsules to the copepod Acartia tonsa (Stancheva et al., 2015). The second hypothesis is supported by recent observations of zooplankter hyperactivity following short-term exposure to pollutants, regardless of their mode of action (Cailleaud et al., 2011b; Michalec et al., 2013a; Chevalier et al., 2015). The third hypothesis derives from dose-response relations in ecotoxicology and from the time-dependent, systemic uptake of nanocapsules by copepods (Stancheva 


\section{Methods}

\subsection{Copepod and algae cultures}

Copepods were sampled from the oligohaline zone of the Scheldt Estuary (Belgium) in July 2012 using a WP2 plankton net drifting in sub-surface water. They were maintained for several generations in the laboratory in aerated $5 \mathrm{~L}$ aquariums under optimal conditions for reproduction and development i.e. at salinity of 15 (filtered and sterilised sea water from the English channel adjusted to salinity with deionised water) and at $18^{\circ} \mathrm{C}$ (Devreker et al., 2009). Copepods were fed in excess on a mixed diet of Rhodomonas baltica and Isochrysis galbana from the laboratory culture, harvested during the exponential growth phase and centrifuged. Algae were grown in aerated $6 \mathrm{~L}$ flasks in sterilised sea water, under a fluorescent light:dark cycle of 12L:12D and in Conway medium.

\subsection{Preparation of nanocapsules}

Lipid nanocapsules were formulated at a nominal size of $50 \mathrm{~nm}$ using the phase inversion method of an oil/water system described in Heurtault et al. (2002). Pollutants were first solubilized in Labrafac ${ }^{\mathrm{TM}}$ Lipophile WL 1349. The oil phase was mixed with Solutol@ HS 15 at $19.1 \%$, Phospholipon $囚 90 \mathrm{G}$ at $3.0 \%, \mathrm{NaCl}$ at $1.7 \%$ and distilled water at $42.9 \%$. The final concentration of Labrafac was 33\%. Labrafac, Phospholipon and Solutol were generously provided by Gattefossé (Saint-Priest, France), Phospholipid GmbH (Cologne, Germany) and Laserson (Etampes, France). The mixture was heated and cooled for three cycles from $60^{\circ} \mathrm{C}$ to $90^{\circ} \mathrm{C}$ under magnetic stirring. The suspension was cooled to $78^{\circ} \mathrm{C}$ and $3.3 \mathrm{~mL}$ of distilled water were added. The concentration of pollutants was $1 \%$ of the total mass of the oily core (Labrafac and Phospholipon). The mean diameter of the lipid nanocapsules was determined by dynamic light scattering (Zetasizer@ Nano ZS) before and after encapsulation and ranges from 46 to $53 \mathrm{~nm}$. Pollutant loading was determined by reversed-phase high performance liquid chromatography (RP-HPLC, Shimadzu LC2010-HT) on a $5 \mu \mathrm{m} \mathrm{C}_{4}$ QS Uptisphere ${ }^{\circledR} 300 \AA 250 \times 4.6 \mathrm{~mm}$ column (Interchim, Montluçon, France) heated at $40^{\circ} \mathrm{C}$. The mobile phase was a mixture of trifluoroacetic acid at $0.05 \%$ in $\mathrm{H}_{2} \mathrm{O}$ and 
$\mathrm{CH}_{3} \mathrm{CN}$ at a flow rate of $1 \mathrm{~mL} \mathrm{~min}^{-1}$. The analysis shows that pollutants are entrapped in the lipid nanocapsules with high efficiency (above 95\%) (Stancheva et al., 2015). Leakage and stability measurements were performed 2 days after synthesis by placing lipid nanocapsules $\left(0.4 \mathrm{mg} \mathrm{ml}^{-1}\right)$ containing either PAHs or PCB in brackish water (salinity 15 ) and at $20^{\circ} \mathrm{C}$. The amount of pollutants leaking from the nanocapsules was determined after gel filtration by RP-HPLC following the procedure described above. Physical stability was estimated by measuring the mean diameter via dynamic light scattering. Nanocapsules loaded with pollutants showed good stability over the duration of our measurements (i.e. $24 \mathrm{~h}$ ) without any apparent leakage of pollutants or change in diameter (Fig. S1). Nanocapsules were purified by gel filtration on PD-10 columns before analysis and measurements.

\subsection{Preparation of test solutions}

The first test solution consisted of lipid nanocapsules loaded with pyrene (CAS No. 129-00-0), phenanthrene (CAS No. 85-01-8) and fluoranthene (CAS No. 206-440) (analytical standard; Fisher Scientific France). We selected pyrene, phenanthrene and fluoranthene because of their widespread occurrence in the aquatic environment and their preferential accumulation in calanoid copepods (Almeda et al., 2014b). The final concentration of each PAH in the experimental aquarium was $0.2 \mathrm{nM}$ and the total concentration was $116 \mathrm{ng} \mathrm{L}^{-1}$. The second solution consisted of capsules loaded with PCB 153 (CAS No. 35065-27-1). We selected this congener because of its major occurrence in estuarine sediments and its transfer to E. affinis (Cailleaud et al., 2007a). The final concentration of PCB 153 in the aquarium was $216 \mathrm{ng} \mathrm{L}^{-1}$. These concentrations are within the upper range observed in several major European estuaries (Fernandes et al., 1997; Cailleaud et al., 2007a, 2009b). They are below the 96-h non-observed effect concentration (NOEC) of PCBs in Tigriopus japonicus, which was estimated at $0.5 \mathrm{mg} \mathrm{L}^{-1}$ and $0.6 \mathrm{mg} \mathrm{L}^{-1}$ (Lee et al., 2007; Guo et al., 2012), and below the 10-day NOEC survival of benzo[a]pyrene in E. affinis, estimated at $12 \mu \mathrm{g} \mathrm{L}^{-1}$ (Forget-Leray et al., 2005). We also conducted identical measurements using empty capsules. The concentration of empty capsules was similar to that of loaded capsules $\left(15 \mu \mathrm{g} \mathrm{L}^{-1}\right)$. 


\subsection{Experimental setup and recording conditions}

We recorded the motion of copepods using three synchronized CCD cameras (AVT GE 1050), fitted with $25 \mathrm{~mm}$ lenses and controlled via an instance of the StreamPix5 (Norpix) acquisition software. A three-camera system facilitates the establishment of stereoscopic correspondences as it resolves most matching ambiguities (Dracos, 1996). The cameras were positioned at different viewing angles in front of a $10 \times 10 \times 11 \mathrm{~cm}^{3}$ acrylic glass aquarium filled with $1 \mathrm{~L}$ of filtered water at salinity 15 and at $18^{\circ} \mathrm{C}$. The recording frequency was 60 frames per second at one megapixel resolution. All but one of the inner faces of the aquarium were coated to prevent reflection of light. We conducted all measurements in the absence of food to prevent synergistic effects (Souissi et al., 2010) and in a dark room, using two arrays of infrared $(850 \mathrm{~nm})$ light-emitting diodes as the light source to prevent phototaxis. We limited our observation volume to a $9 \times 9 \times 9 \mathrm{~cm}^{3}$ cube centred in the middle of the aquarium. We calibrated the cameras using images of a calibration block with target dots of known coordinates, and we performed an additional dynamic calibration based on the images of moving particles (Liberzon et al., 2012). The calibration object consisted of a machined block on which 135 reference points were evenly distributed along the three directions. We checked copepods for integrity under a microscope and selected healthy individuals only. Because E. affinis males and females have different detoxification abilities (BoulangéLecomte et al., 2014) that translate into different behavioural responses to toxicants (Michalec et al., 2013a), we investigated separately males and females. We transferred groups of 60 copepods (mean total body length: $1 \mathrm{~mm}$ for females and $0.9 \mathrm{~mm}$ for males) into the experimental aquarium and allowed them to acclimate for $5 \mathrm{~min}$ in the dark. We recorded their swimming behaviour for $25 \mathrm{~min}$. We conducted measurements under a constant ambient temperature of $15^{\circ} \mathrm{C}$ to compensate from the increase in temperature caused by the diode arrays. Water temperature in the experimental aquarium remained constant at $18^{\circ} \mathrm{C}$. We conducted all measurements at the same time of day and with new copepods from the stock culture. 


\subsection{Reconstruction of three-dimensional trajectories}

Knowing the camera intrinsic and extrinsic parameters from the calibration procedure, we established correspondences between particle image coordinates and derived the three-dimensional positions of the moving organisms by forward intersection, introducing their coordinates as unknowns in the augmented projection model (Maas et al., 1993; Malik et al., 1993). We processed the image sequences and tracked copepods using an algorithm based on image and object space information (Willneff and Gruen, 2002). We glued segments belonging to the same trajectory using a spatio-temporal matching assignment (Saha et al., 2014) and we smoothed trajectories with a SavitzkyGolay filter to improve the measurement of velocity (Wolf et al., 2012). We filtered out artefacts originating from the tracking and gluing procedures and rejected trajectories lying outside the observation volume to avoid boundary effects.

\subsection{Trajectory analysis}

We first considered the kinematic properties of the motion. Eurytemora affinis males and females show a continuous slow swimming pattern interrupted by frequent relocation jumps (Movie S1) (Michalec et al., 2015). The slow forward motion derives from the creation of feeding currents accomplished by the high-frequency vibration of the cephalic appendages (Kiørboe et al., 2014). Relocation jumps have been commonly observed in calanoid copepods and result in a sequence of small velocity bursts leading to an unsteady motion (Jiang and Kiørboe, 2011). As a first metric, we measured the magnitude of the instantaneous velocity as $u=\left(u_{x}{ }^{2}+u_{y}{ }^{2}+u_{z}{ }^{2}\right)^{0.5}$ where the indices $x, y$ and $z$ refer to the three cartesian axes of the reference frame. We estimated the probability density functions of $u$ to quantify the effects of exposure on the swimming velocity. To better assess how pollutants affect jump behaviour, an important component of copepod motion, we extracted relocation jumps from the velocity time series and we quantified variations in their amplitude and duration. To identify relocation jumps, we first filtered out the high-frequency modes of the velocity signal which are associated with individual leg strokes during the same relocation jump and which also result from inaccuracies in the determination of particle positions. We used a fourth-order lowpass Butterworth filter with a cut-off frequency set at $10 \mathrm{~Hz}$. This 
filter attenuated high frequencies while preserving the sharpness of individual jumps. Because cruising copepods show low frequency fluctuations (i.e. over several seconds) in their swimming speed, we adjusted for the variable baseline of their velocity time series. We estimated this baseline within multiple shifted windows and regressed it to the window points using a spline approximation. We identified all jumps using a wavelet-based peak detection method. Change in body orientation during cruising often resulted in small bursts in velocity that were discarded from the analysis by setting a $5 \mathrm{~mm} \mathrm{~s}^{-1}$ threshold for the jump amplitude. The effects of filtering, baseline subtraction and peak detection procedures are illustrated for a typical example velocity time series in Fig 1.

We computed the root mean square displacement, defined as $r m s d=\left\langle\delta X_{t}^{2}\right\rangle^{0.5}$ where $\delta X_{t}$ is the displacement of a copepod at time $t$ relative to its initial position. We estimated the geometrical complexity of the motion by computing the box-counting dimension of the trajectories. The box-counting dimension is commonly employed to characterize the degree of space occupation of zooplankton trajectories (Cianelli et al., 2009; Michalec et al., 2013a). We created a three-dimensional bounding box around each trajectory. The origin of this bounding box lay at the intersection of the planes defined by the minimal coordinates of the trajectory and its height, length and depth were equal to the maximal displacement of the copepod along each dimension. We superimposed a three-dimensional grid of varying mesh size on the trajectory and we counted the number of occupied boxes versus the mesh size. This number increases with decreasing mesh size, leading to the power-law relationship $N(l) \sim l^{-D}$ where $l$ is the mesh size, $N(l)$ is the number of occupied boxes and $D$ is the box-counting dimension. The mesh size followed a geometric sequence with a maximal and minimal cut-off values set to half the embedding volume and $0.5 \mathrm{~mm}$, respectively. Because copepods jump while swimming, relatively large separation distances between consecutive positions may result in lacunarity during the box-counting procedure. Consequently, we characterized each swimming track using a cubic spline interpolation and built a new trajectory by extrapolating new positions at equal separation distance along the original curve. This separation distance was always shorter than the minimal mesh size. The box-counting dimension was given by the slope of the power fit of the log-log plot of 
the number of occupied boxes versus mesh size.

\section{Results}

\subsection{Ingestion of nanocapsules}

Nanocapsules filled with DiI at $0.1 \%$ and PCB 153 at $1 \%$ are observed on the cuticle after $30 \mathrm{~min}$ of exposure and both on the cuticle and inside the digestive track at $\mathrm{t}=3 \mathrm{~h}$ and $\mathrm{t}=24 \mathrm{~h}$ (Fig 2) (Stancheva et al., 2015). This suggests that any changes in swimming activity observed at $\mathrm{t}=0 \mathrm{~h}$ result from contact toxicity, and that any variation in behaviour observed at $\mathrm{t}=3 \mathrm{~h}$ and $\mathrm{t}=24 \mathrm{~h}$ result from a combination of contact and systemic toxicity. The concentration of capsules inside the gut of the animals increases substantially from $\mathrm{t}=3 \mathrm{~h}$ to $\mathrm{t}=24 \mathrm{~h}$, suggesting a higher systemic toxicity at the maximal exposure duration. Similarly, the adhesion of capsules on the surface of the organisms, both on the cuticle and on the appendages, increases drastically with exposure duration.

\subsection{Swimming activity}

During the measurements, copepods spent time swimming actively and sometimes resting on the walls or at the bottom of the aquarium. Immobile animals were not tracked because they were outside the investigation volume. Consequently, the number of three-dimensional coordinates provides a general assessment of copepod swimming activity, because it reflects directly the number of organisms actively swimming in the aquarium. In males, exposure to empty nanocapsules causes a more than three-fold increase in the number of coordinates at $\mathrm{t}=0 \mathrm{~h}$ compared to clean water (Table 1 ). Compared to $\mathrm{t}=0 \mathrm{~h}$, swimming activity decreases at $\mathrm{t}=3 \mathrm{~h}$ and $\mathrm{t}=24 \mathrm{~h}$ but remains higher than in clean water. A marked increase in activity is also observed during exposure to nanocapsules filled with PAHs and with PCB. For these two conditions, activity is the highest at $t=3 \mathrm{~h}$. At $\mathrm{t}=24 \mathrm{~h}$, the number of coordinates decreases substantially but remains above that observed with empty capsules. The increase in swimming activity is also visible in females, but is much less pronounced than in males. In the presence of empty nanocapsules, the number of coordinates decreases at $t=0 \mathrm{~h}$, increases substantially at $\mathrm{t}=3 \mathrm{~h}$ and reduces again below control values at $\mathrm{t}=24 \mathrm{~h}$. Swimming activity 
increases strongly during exposure to PAHs and PCB, above that observed with the empty capsules. The strongest effect is observed with nanocapsules filled with PCB, which causes at $\mathrm{t}=3 \mathrm{~h}$ a more than two-fold increase in the number of coordinates. Activity slows down substantially at $\mathrm{t}=24 \mathrm{~h}$.

\subsection{Swimming velocity}

Over time, velocity remains relatively similar in males and females swimming in clean water, as evidenced by the overlap of the probability density functions at $\mathrm{t}=0 \mathrm{~h}$, $\mathrm{t}=3 \mathrm{~h}$ and $\mathrm{t}=24 \mathrm{~h}$ (Fig. 3). In males, velocity averages are $3.4 \mathrm{~mm} \mathrm{~s}^{-1}$ for the three exposure durations (Table 2). In females, velocity averages are $2.9 \mathrm{~mm} \mathrm{~s}^{-1}$ at $\mathrm{t}=0 \mathrm{~h}$ and $\mathrm{t}=3 \mathrm{~h}$ and $2.8 \mathrm{~mm} \mathrm{~s}^{-1}$ at $\mathrm{t}=24 \mathrm{~h}$. In both genders, exposure to empty nanocapsules results in an increase in swimming velocity that reaches its maximum at $t=3 \mathrm{~h}$. In males, this increase is evidenced by a shift of the peak of the probability density function toward higher cruising velocities (from $2 \mathrm{~mm} \mathrm{~s}^{-1}$ in control condition to $4 \mathrm{~mm} \mathrm{~s}^{-1}$ with unloaded carriers) and by a higher proportion of medium velocity values (from 5 to $10 \mathrm{~mm} \mathrm{~s}^{-1}$ ) whereas in females, both medium and large velocity values (from 5 to $30 \mathrm{~mm} \mathrm{~s}^{-1}$ ) increases in proportion. In both genders, the presence of PAHs reduces the effects caused by the empty capsules; in males, the mean velocity returns to control value at $\mathrm{t}=24 \mathrm{~h}$. Exposure to nanocapsules filled with PCB causes the strongest effects. Velocity increases immediately to $4.8 \mathrm{~mm} \mathrm{~s}^{-1}$ in males and to $4.2 \mathrm{~mm} \mathrm{~s}^{-1}$ in females; this increase is much larger than that observed for empty capsules. Large differences are also visible in the probability density functions, which show in both genders a significantly higher proportion of medium and large velocity values (above $4 \mathrm{~mm} \mathrm{~s}^{-1}$ ) and a lower proportions of low velocity values (below $4 \mathrm{~mm} \mathrm{~s}^{-1}$ ). In males, for empty nanocapsules and nanocapsules filled with pollutants, the proportion of large velocity values (above $10 \mathrm{~mm} \mathrm{~s}^{-1}$ ) decreases strongly (for empty capsules and capsules loaded with PCB) or moderately (for carriers loaded with PAHs) at $\mathrm{t}=24 \mathrm{~h}$, below the control curves. In females, velocity probability density functions remain always above the control curves at moderate to strong magnitudes. 


\subsection{Amplitude and duration of jumps}

We illustrate the effects of exposure on the jump behaviour of males, because they show a more complex and pronounced response than females. Results show that $E$. affinis swimming in clean water displays two types of relocation jumps that differ in their amplitude and duration (as evidenced by the bi-modal probability density functions in Fig. 4). The ecological significance of these two types of jumps is unclear; short jumps of limited amplitude may be associated with weak repositioning events that have been previously observed in calanoid copepods (Kiørboe et al., 2010). The distribution of both the magnitude and duration of jumps differs strongly between conditions. Exposure to empty nanocapsules results at $\mathrm{t}=3 \mathrm{~h}$ and $\mathrm{t}=24 \mathrm{~h}$ in a progressive decrease in the magnitude of jumps that agrees well with the trend observed in the probability density functions. It also causes a marked, time-dependent increase in the proportion of short jumps. Exposure to PAHs cancels the effects of the empty capsules on jump magnitude but decreases slightly the proportion of both short and long jumps; consequently, the distribution of jump duration spreads over a larger range of values. Exposure to nanocapsules filled with PCB results in a substantial decrease in jump magnitude; effects occur immediately and not progressively as with empty capsules. The distribution of jump duration shifts toward shorter values, with a substantial decrease in the proportion of long jumps.

\subsection{Root mean square displacement}

The root mean square displacement shows important variations between genders and between experimental conditions (Fig 5). Exposure to empty nanocapsules causes in both males and females a marked increase in the spatial extent of their motion, with little effects at $\mathrm{t}=0 \mathrm{~h}$ and maximal effects at $\mathrm{t}=3 \mathrm{~h}$ (in males) and at $\mathrm{t}=24 \mathrm{~h}$ (in females). Exposure to PAHs reduces considerably the influence of empty capsules; slightly higher values are observed in females at $\mathrm{t}=3 \mathrm{~h}$ and $\mathrm{t}=24 \mathrm{~h}$, but not in males. The largest effects are observed in the presence of nanocapsules filled with PCB, which cause a considerable increase in the spatial extent of copepod motion. Effects occur immediately and not progressively as with empty capsules; at $t=24 \mathrm{~h}$, they reduce substantially in males but only slightly in females. Because larger values of the root mean 
square displacement can result from higher swimming velocities or from a straighter motion, we also quantify the geometrical properties of the trajectories.

\subsection{Box-counting dimension}

Despite slight variations in the mean values, the box-counting dimension of the trajectories remains statistically similar between the three periods of recording for males and females swimming in control water (Kruskal-Wallis test, $p>0.05$ ) (Table 3 ). It remains statistically similar in males and females exposed to empty capsules at $\mathrm{t}=0 \mathrm{~h}$ and $\mathrm{t}=3 \mathrm{~h}(p>0.05)$ but decreases slightly (in males) and substantially (in females) at $\mathrm{t}=24 \mathrm{~h}(p<0.01)$. It also remains similar in both genders during exposure to PAHs and PCB $(p>0.05)$.

There is at $\mathrm{t}=0 \mathrm{~h}$ no statistically significant difference in the degree of space occupation for males swimming in clean water and in the presence of empty capsules or capsules loaded with pollutants $(p>0.05)$. However, the trend in the $p$-value after pairwise comparison (multiple comparison of mean ranks) suggests a slight influence of the empty carriers $(p=0.05)$, and that exposure to pollutants reduces this influence ( $p=0.53$ between control condition and exposure to PAHs and $p=0.98$ between control condition and exposure to PCB). Indeed, we find significant differences between the box-counting dimension of males exposed to empty capsules and to capsules loaded with contaminants $(p<0.01)$ despite very similar mean values. At $\mathrm{t}=3 \mathrm{~h}$, the box-counting dimension of males swimming in clean water differs from that of males exposed to empty capsules $(p<0.01)$ and to capsules loaded with PCB $(p<0.01)$ but is similar to that of males exposed to carriers loaded with PAHs $(p>0.05)$. Pairwise comparison indicates that empty capsules and capsules loaded with PCB induce statistically similar effects $(p>0.05)$. However, no substantial difference is visible in the mean values. At $t=24 \mathrm{~h}$, the box counting dimension of males swimming in clean water is statistically similar to that of copepods exposed to pollutants $(p>0.05)$. A slightly lower degree of space occupation is visible during exposure to empty capsules $(p<0.01)$.

In females, at $\mathrm{t}=0 \mathrm{~h}$, exposure to empty capsules decreases strongly the degree of space occupation compared to control condition (Table 3). The box-counting dimen- 
sion reduces further with particles loaded with PAHs $(p<0.01)$. It increases again with particles filled with PCB; for this condition, the degree of space occupation is statistically similar to that observed with empty capsules $(p>0.05)$, but is still much lower than in control condition $(p<0.01)$ and not statistically different from that observed with PAHs $(p>0.05)$. At $\mathrm{t}=3 \mathrm{~h}$, the box counting dimension of females exposed to empty capsules and capsules loaded with PAHs and PCB is similar $(p>0.05)$ and substantially lower than in control condition $(p=0.01)$. At $\mathrm{t}=24 \mathrm{~h}$, exposure to empty capsules further reduces the degree of space occupation to its lowest value $(p<0.01)$. The box-counting dimension increases slightly in the presence of PAHs but remains different from that observed in clean water $(p<0.01)$ and similar to that observed with empty carriers. It increases further during exposure to PCB but the difference is not statistically significant $(p>0.05)$.

\section{Discussion}

We assessed the behavioural response of the calanoid copepod E. affinis to pollutants at concentrations found in its environment. We used lipid nanocapsules to deliver hydrophobic pollutants into the digestive track of the animals. We obtained both contact and trophic exposure without using contaminated phytoplankton and without relying on a solvent. We show that despite their lack of toxicity, empty nanocapsules induce changes in the swimming behaviour of copepods. Their confounding effects complicate interpretation of the results obtained with loaded capsules. However, clear trends are visible. Exposure to nanocapsules filled with pollutants exacerbated hyperactivity at $\mathrm{t}=0 \mathrm{~h}$, which agrees with our second hypothesis. At $\mathrm{t}=3 \mathrm{~h}$, exposure to PAHs reduces substantially the effects of empty capsules, but exposure to PCB 153 exacerbates hyperactivity.

Solutol is a nonionic solubilizer widely used as emulsifying agent in the preparation of lipophilic pharmaceutical active agents. It consists of polyglycol mono- and diesters of 12-hydroxystearic acid and free polyethylene glycol. Solutol shows excellent biocompatibility (Coon et al., 1991; Vonarbourg et al., 2009) and is not toxic to copepods (Stancheva et al., 2015). It seemed to be the ideal solubilizer for the preparation 
of nanocapsules, and we hypothesized that copepods would not react to its presence. However, after $3 \mathrm{~h}$ of exposure, unloaded capsules caused strong hyperactivity and higher swimming velocities. They also resulted in a larger spatial extent of copepod motion, and in straighter trajectories (especially in females). This behavioural response resembles that found in our earlier work, in which we exposed E. affinis to sub-lethal concentrations of pollutants having different modes of action (Michalec et al., 2013a). We observed a substantial increase in swimming speed, and we suggested an avoidance behaviour caused by contact between chemoreceptors on the cuticle and dissolved molecules. Avoidance behaviour and hyperactivity are often observed in aquatic organisms independently of the toxic properties of the chemicals. Avoidance behaviour was identified in Daphnia magna exposed to dissolved deltamethrin, chlorothalonil and nitrofen (Ren et al., 2009), in D. longispina exposed to free copper (Lopes et al., 2004) or in the calanoid copepod Pseudodiaptomus annandalei exposed to ethanol (Michalec et al., 2013b). Hyperactivity was evidenced in Daphnia following fullerene exposure (Lovern et al., 2007). We suggest here a similar mechanism for the empty capsules. Our results also confirm that even non-toxic molecules can trigger increased activity and marked changes in behaviour (Steinke et al., 2004). Finally, we observed stronger behavioural effects at $\mathrm{t}=3 \mathrm{~h}$ than at $\mathrm{t}=0 \mathrm{~h}$, and a reduced response at $\mathrm{t}=24 \mathrm{~h}$. We also observed a time-dependent adhesion of empty nanocapsules on the external carapace and appendages of the animals, as previously described in small crustaceans exposed to diverse nanoparticles (Baun et al., 2008). We suggest that the higher response at $\mathrm{t}=3 \mathrm{~h}$ comes from a higher contact effect. Conversely, the substantial decrease in swimming activity at $\mathrm{t}=24 \mathrm{~h}$ suggests fatigue. This view is consistent with the lower proportion of high velocity values and with the marked decrease in jump magnitude and duration observed in males after $24 \mathrm{~h}$ of exposure. As shown in Fig. $3 \mathrm{~A}$, the peak of the probability density function of the velocity shifts to the right, indicating higher cruising velocities. Because $E$. affinis spends most of its time swimming slowly, higher cruising velocities may cost copepods a substantial fraction of their energy budget (Buskey, 1998). In our measurements, after one day of exposure, males are only capable of shorter and weaker jumps. In females, the effects of empty nanocapsules are only visible at higher velocity values. There is no increase in cruising velocity, and no reduction in the proportion of 
large velocity values after $24 \mathrm{~h}$ of exposure.

The narcotic effects of PAHs on aquatic organisms is well established. A narcotic effect is defined as an apparently reversible alteration of the membrane fluidity and protein function caused by the accumulation of hydrophobic pollutants in the lipid bilayer region (van Wezel and Opperhuizen, 1995). This nonspecific partitioning of the chemical in nerve tissue results in anaesthetic effects. In Michalec et al. (2013a), we observed an immediate increase in swimming speed following exposure to a mixture of pyrene, phenanthrene and fluoranthene at $40 \mathrm{ng} \mathrm{L}^{-1}$. Because there was no incubation period and concentrations were extremely low, this unexpected response was linked to the initial hyperactivity that often occurs in response to low doses of toxicants or during the first stage of exposure. Increased activity and velocity at low levels of toxicity have been reported in a variety of small aquatic organisms and in response to diverse pollutants (Kirkpatrick et al., 2006; Ren et al., 2007; Sornom et al., 2012; Chevalier et al., 2015). Higher concentrations of toxicants or longer exposure are expected to result in lower swimming activity, reflecting the metabolic cost of detoxification (Sokolova et al., 2012) or indicating loss of coordination due to impaired physiological functions (Escher and Hermens, 2002). Low-dose stimulation and high-dose inhibition have been observed in Artemia and in the rotifer Brachionus plicatilis exposed to zinc pyrithione and to a carbamate pesticide (Garaventa et al., 2010), and in the amphipod Corophium volutator exposed to water accommodated fraction of weathered crude oil (Kienle and Gerhardt, 2008). The slightly higher velocity observed here at $\mathrm{t}=0 \mathrm{~h}$ (compared to the unloaded carriers) suggests an additive effect of PAHs and empty capsules and tends to indicate contact toxicity and escape reaction. Additive effects of waterborne contaminants on swimming behaviour were also observed in D. pullex exposed to 4nonylphenol and diazinon (Zein et al., 2015). On the opposite, the depressed mean velocity at $\mathrm{t}=3 \mathrm{~h}$ (compared to the unloaded carriers) and to an even greater extend at $\mathrm{t}$ $=24 \mathrm{~h}$ agrees well with the narcotic properties of PAHs and suggests systemic toxicity due to ingestion of loaded capsules. These narcotic effects have been widely reported in the literature for different species of copepods and long exposure durations (Cowles, 1983; Barata et al., 2005; Almeda et al., 2014b), and they agree well with our second hypothesis. Surprisingly, we observed in our measurements a substantial increase, 
rather than a reduction, in the level of spontaneous swimming activity (in comparison to unloaded capsules). This result contrasts with the reduction in swimming speed and suggests a complex behavioural toxicity of PAHs. The slight decrease in the proportion of high velocity values after one day of exposure differs from the marked reduction observed with the empty capsules; the opposite influence of unloaded carriers and PAHs on cruising velocity (and hence fatigue) may explain this effect. Finally, because exposure to PAHs reduced both swimming velocity and the proportion of straighter trajectories (in comparison to unloaded capsules), the root mean square displacement is less than with unloaded capsules. Similarly, jump magnitude shows little variation with control values.

Pollutants can act through different modes of action, causing a tremendous variety of species-specific effects (Russom et al., 1997). Our knowledge on the toxic effects of PCBs in zooplankters is limited and insufficient to link the observed behavioural response to molecular toxicity. In our measurements, exposure to PCB induced very strong hyperactivity. The increase in mean swimming speed is much more significant than with empty capsules and occurs immediately, both in males and in females. These results suggest strong contact toxicity and agree well with our second hypothesis. The level of spontaneous swimming activity and the mean swimming velocity drop substantially after one day of exposure. Because at $\mathrm{t}=24 \mathrm{~h}$ the probability density function of the velocity deviates substantially from that observed with empty capsules (in both genders) and over a wider range of values in males (from 5 to $15 \mathrm{~mm} \mathrm{~s}^{-1}$ ), our results suggest systemic effects of PCB, in addition to fatigue caused by the unloaded carriers. These results tend to agree with our third hypothesis. Large differences are also visible between genders at $\mathrm{t}=24 \mathrm{~h}$ in the spatial properties of motion. In males, the degree of trajectory sinuosity following exposure to PCB does not differ substantially from that observed in clean water and with empty capsules. Consequently, the root mean square displacement reduces strongly with swimming velocity, toward control values. In females, trajectories are straighter in the presence of empty capsules and this effect persists during exposure to pollutants. The spatial extent of their motion (compared to control condition) remains larger than in males, despite the strong reduction in swimming speed. 
We observed a much stronger hyperactivity and a much larger increase in swimming speed in males than in females, for both empty capsules and capsules loaded with PAHs. We also found that a $24 \mathrm{~h}$ exposure to PCB had less impact on the swimming velocity in females than in males, with effects visible over a much smaller range of velocity values (Fig. 3). Several studies have pointed out the greater sensitivity of male copepods to various environmental stressors, for instance salinity shocks (Chen et al., 2006), diatom aldehydes (Taylor et al., 2007) or insecticides (Medina et al., 2002; Chandler et al., 2004). This greater sensitivity translates into different behavioural response: $P$. annandalei males react much more strongly than females to a progressive salinity increase and to a diatom toxin (Michalec et al., 2012, 2013b). Boulangé-Lecomte et al. (2014) observed a weaker constitutive expression of the two major heat shock proteins (Grp78 and Hsp90A) in E. affinis males than in females, indicating gender-specific stress tolerance and suggesting that substantial basal levels of expression may give females higher tolerance to stress conditions. Induction of heat shock proteins occurs rapidly in calanoid copepods (Gonzalez and Bradley, 1994; Xuereb et al., 2012) but whether these enzymes contributes substantially to the higher resistance of females to chemical stress remains unknown. Other xenobiotic-metabolizing enzyme systems such as the CYP monooxygenase or glutathione S-transferase are mainly responsible for the detoxification of large hydrophobic and toxic xenobiotic from the tissues (Lauritano et al., 2012). Whether these enzymes give female copepods more efficient and effective mechanisms involved in stress response than males has yet to be tested.

Very few studies have linked changes in swimming behaviour induced by pollutants to changes in ecological processes in zooplanktonic organisms. One-day exposure to sublethal concentrations of the water accommodated fraction of crude oil significantly increased the positive phototactic behaviour of the calanoid copepod Calanus finmarchicus, which may lead to changes in the vertical distribution of this species after offshore oil-spills (Miljeteig et al., 2013). Exposure to PCBs affected the response of Daphnia to the presence of fish kairomone and toxic filamentous cyanobacteria, which may results in an incorrect response to these biotic threats (Bernatowicz and Pijanowska, 2011). Fullerenes altered the vertical migration response of D. magna to the presence of food (Brausch et al., 2011). In calanoid copepods, the ecological 
significance of behavioural impairments on trophic interactions remains to be tested, but we can offer some assumptions based on the literature. Swimming behaviour has greatly contributed to the evolutionary success of calanoid copepods (Kiørboe, 2011). Behaviour mediates how they exploit their environment and interact with other organisms. Consequently, these small animals have evolved optimal motion strategies that are believed to enhance mating encounters and foraging efficiency and minimize dangerous meetings with planktonic predators (Visser and Kiørboe, 2006; Kiørboe, 2008; Bianco et al., 2014). Variations in the optimal configuration of their trajectories following exposure to pollutants may destabilize the trade-off between beneficial and detrimental encounters (Visser, 2007). In Dodson et al. (1995) for instance, individual Daphnia treated with the pesticide carbaryl were preferentially eaten by bluegill sunfish, because of marked changes in their motility pattern. Hyperactivity and swimming faster may also lead to impairment in behavioural processes and to a reduced fitness because they determine both conspicuousness to predators and encounter rates. For instance, stripped bass fed at higher rates on nauplii E. affinis that were hyperactive due to exposure to copper (Sullivan et al., 1983). The success of copepods in feeding, reproducing and escaping predation depends on their relative velocity with respect to their prey, their mate and their predator from the time of the detection to the end of the interaction (Adhikari and Longmire, 2013). Compounds that influence the evasive ability of an organism may therefore directly affect its ability to avoid predation. Souissi et al. (2013) observed changes in swimming behaviour caused by fatigue, and reduced mating success in E. affinis following epibiont cilliate infestation. Similar effects on mating success are likely to occur following exposure to pollution, but this remains to be tested. Hyperactivity may also impair the ability of copepods to detect food particles in their feeding currents. Jiang et al. (2002b) demonstrated that a copepod swimming slowly can use chemoreception to remotely detect individual algae entrained by its surrounding flow field, whereas this is not feasible in fast-swimming individuals. Using numerical simulation, Jiang et al. (2002a) also showed that swimming slowly is more energetically efficient in terms of relative capture volume per energy expended than swimming faster. Irrespective of their feeding behaviour and size, copepods converge on optimal, size-independent specific clearance rates that maximize the net energy gain 
over the predation risk (Kiørboe and Jiang, 2013). Variation in the properties of their motion following fatigue or physiological incapacitation may result in a switch from preferred swimming strategies to less optimal behaviours.

Although we did not replicate measurements, we minimised the effects of unknown sources of variance by conducting measurements within a few days to prevent possible differences in swimming behaviour between generations, and with adult copepods from the same stable culture to avoid possible effects caused by different rearing conditions (Souissi et al., 2010). We have also recorded the motion of many organisms to account for the high inter-individual variability in copepod behaviour (Michalec et al., 2012).

In copepod ecology, little toxicological research has sought to integrate behavioural effects with molecular and physiological processes. It is therefore difficult to relate our results to observations from the literature. Future studies are needed to improve our knowledge on the complex impact of toxicants on zooplankton behaviour. The difference between contact and systemic behavioural toxicity of many common aquatic pollutants is not well studied. Nanocapsules offer the advantage that they mimic trophic exposure while eliminating the need of phytoplankton. They also represent an innovative alternative to the use of solvent, and are stable and homogeneously distributed in the water medium. It is our hope that this work will motivate further research on the development of nanosystems for behavioural testing. Calanoid copepods are only beginning to be considered as model species in behavioural assays. Our results add some new insights into the interactions between waterborne pollution and copepods. They prompt us to further explore how these important organisms react to the mixture of toxicants present in their environment.

\section{Authors' contributions}

S. Souissi and R. B. designed the experiments. A. S. and S. Souissi provided the test organisms. A. S. contributed to copepod acclimation and sorting. S. Stancheva, A. B. and R. B. synthesised the lipid nanocapsules and quantified pollutant encapsulation rate and nanocapsule stability. F.-G. M. carried out the measurements, performed data analysis and wrote the manuscript. M. H. participated in data analysis and helped draft 
the manuscript. All authors gave final approval for publication.

\section{Acknowledgments}

We are thankful to Y.-J. Pan for culturing copepods and algae and for his assistance during the experiments. We thank C. Spriet for his help in obtaining confocal microscopy images of copepods, D. Menu for manufacturing the experimental setup and the anonymous reviewers for their constructive comments.

\section{Funding statement}

S. Souissi and R. B. gratefully acknowledge financial support from Lille 1 University (BQR 2014 Convergence grant). F.-G. M. and M. H. acknowledge support from Swiss National Science Foundation (SNSF) grant No. 144645 and ETH grant No. 2914-1. S. Stancheva was supported by a CIFRE grant from PFI Nouvelles Vagues (Boulogne-sur-Mer, France). This work is a contribution to the bilateral agreement between ETH Zurich and Lille 1 University, and to the ZOOGLOBAL project founded by GIP Seine-Aval. The funding sources had no involvement in study design and in the analysis and interpretation of data.

\section{References}

\section{References}

Adhikari, D., Longmire, E. K., 2013. Infrared tomographic PIV and 3D motion tracking system applied to aquatic predator-prey interaction. Measurement Science and Technology 24, 024011.

Almeda, R., Baca, S., Hyatt, C., Buskey, E. J., 2014a. Ingestion and sublethal effects of physically and chemically dispersed crude oil on marine planktonic copepods. Ecotoxicology 23, 988-1003.

Almeda, R., Wambaugh, Z., Wang, Z., Hyatt, C., Liu, Z., Buskey, E. J., 2014b. Interactions between zooplankton and crude oil: Toxic effects and bioaccumulation of polycyclic aromatic hydrocarbons. PLoS ONE 8, e67212. 
Ardekani, R., Biyani, A., Dalton, J. E., Saltz, J. B., Arbeitman, M. N., Tower, J., Nuzhdin, S., Tavaré, S., 2013. Three-dimensional tracking and behaviour monitoring of multiple fruit flies. Journal of the Royal Society Interface 10, 20120547.

Attanasi, A., Cavagna, A., Del Castello, L., Giardina, I., Jelic, A., Melillo, S., Parisi, L., Pohl, O., Shen, E., Viale, M., 2015. Emergence of collective changes in travel direction of starling flocks from individual birds' fluctuations. Journal of the Royal Society Interface 12, 20150319.

Barata, C., Calbet, A., Saiz, E., Ortiz, L., Bayona, J. M., 2005. Predicting single and mixture toxicity of petrogenic polycyclic aromatic hydrocarbons to the copepod Oithona davisae. Environmental Toxicology and Chemistry 24, 2992-2999.

Baun, A., Hartmann, N. B., Grieger, K., Kusk, K. O., 2008. Ecotoxicity of engineered nanoparticles to aquatic invertebrates: a brief review and recommendations for future toxicity testing. Ecotoxicology 17, 387-395.

Bellas, J., Thor, P., 2007. Effects of selected PAHs on reproduction and survival of the calanoid copepod Acartia tonsa. Ecotoxicology 16, 465-474.

Bernatowicz, P., Pijanowska, J., 2011. Daphnia response to biotic stress is modified by PCBs. Ecotoxicology and Environmental Safety 74, 711-718.

Berrojalbiz, N., Lacorte, S., Calbet, A., Saiz, E., Barata, C., Dachs, J., 2009. Accumulation and cycling of polycyclic aromatic hydrocarbons in zooplankton. Environmental Science and Technology 43, 2295-2301.

Bianco, G., Mariani, P., Visser, A. W., Mazzocchi, M. G., Pigolotti, S., 2014. Analysis of self-overlap reveals trade-offs in plankton swimming trajectories. Journal of the Royal Society Interface 11, 20140164.

Blinova, N. K., Cherkashin, S. A., 2012. The olfactory system of crustaceans as a model for ecologo-toxicological studies. Journal of Evolutionary Biochemistry and Physiology 48, 155-156. 
Boulangé-Lecomte, C., Forget-Leray, J., Xuereb, B., 2014. Sexual dimorphism in Grp78 and Hsp90A heat shock protein expression in the estuarine copepod Eurytemora affinis. Cell Stress and Chaperones 19, 591-597.

Brausch, K. A., Anderson, T. A., Smith, P. N., Maul, J. D., 2011. The effect of fullerenes and functionalized fullerenes on Daphnia magna phototaxis and swimming behaviour. Environmental Toxicology and Chemistry 30, 878-884.

Bunjes, H., 2010. Lipid nanoparticles for the delivery of poorly water-soluble drugs. Journal of Pharmacy and Pharmacology 62, 1637-1645.

Buskey, E. J., 1998. Energetic costs of swarming behavior for the copepod Dioithona oculata. Marine Biology 130, 425-431.

Cailleaud, K., Budzinski, H., Lardy, S., Augagneur, S., Barka, S., Souissi, S., ForgetLeray, J., 2011a. Uptake and elimination, and effect of estrogen-like contaminants in estuarine copepods: an experimental study. Environmental Science and Pollution Research 18, 226-236.

Cailleaud, K., Budzinski, H., Menach, K. L., Souissi, S., Forget-Leray, J., 2009a. Uptake and elimination of hydrophobic organic contaminants in estuarine copepods: An experimental study. Environmental Toxicology and Chemistry 28, 239-246.

Cailleaud, K., Forget-Leray, J., Peluhet, L., LeMenach, K., Souissi, S., Budzinski, H., 2009b. Tidal influence on the distribution of hydrophobic organic contaminants in the Seine Estuary and biomarker responses on the copepod Eurytemora affinis. Environmental Pollution 157, 64-71.

Cailleaud, K., Forget-Leray, J., Souissi, S., Hilde, D., LeMenach, K., Budzinski, H., 2007a. Seasonal variations of hydrophobic organic contaminant concentrations in the water-column of the Seine Estuary and their transfer to a planktonic species Eurytemora affinis (Calanoida, copepoda). Part 1: PCBs and PAHs. Chemosphere 70, 270-280.

Cailleaud, K., Forget-Leray, J., Souissi, S., Lardy, S., Augagneur, S., Budzinski, H., 2007b. Seasonal variation of hydrophobic organic contaminant concentrations in the 
water-column of the Seine Estuary and their transfer to a planktonic species Eurytemora affinis (Calanoid, copepod). Part 2: Alkylphenol-polyethoxylates. Chemosphere 70, 281-287.

Cailleaud, K., Michalec, F. G., Forget-Leray, J., Budzinski, H., Hwang, J. S., Schmitt, F. G., Souissi, S., 2011b. Changes in the swimming behavior of Eurytemora affinis (Copepoda, Calanoida) in response to a sub-lethal exposure to nonylphenols. Aquatic Toxicology 102, 228-231.

Carls, M. G., Short, J. W., Payne, J., 2006. Accumulation of polycyclic aromatic hydrocarbons by Neocalanus copepods in Port Valdez, Alaska. Marine Pollution Bulletin $52,1480-1489$.

Chandler, G. T., Cary, T. L., Volz, D. C., Walse, S. S., Ferry, J. L., Klosterhaus, S. L., 2004. Fipronil effects on estuarine copepod (Amphiascus tenuiremis) development, fertility, and reproduction: a rapid life-cycle assay in 96-well microplate format. Environmental Toxicology and Chemistry 23, 117-124.

Chang, S. I., Reinfelder, J. R., 2002. Relative importance of dissolved versus trophic bioaccumulation of copper in marine copepods. Marine Ecology Progress Series 231, 179-186.

Chen, A., Sheng, J., Lin, Q., Gao, Y., Lv, J., 2006. Effect of salinity on reproduction and survival of the copepod Pseudodiaptomus annandalei Sewell, 1919. Aquaculture $258,575-582$.

Chevalier, J., Harscoët, E., Keller, M., Pandard, P., Cachot, J., Grote, M., 2015. Exploration of daphnia behavioral effect profiles induced by a broad range of toxicants with different modes of action. Environmental Toxicology and Chemistry DOI: 10.1002/etc.2979.

Cianelli, D., Uttieri, M., Strickler, J. R., Zambianchi, E., 2009. Zooplankton encounters in patchy particle distributions. Ecological Modelling 220, 596-604.

Clotfelter, E. D., Bell, A. M., Levering, K. R., 2004. The role of animal behaviour in the study of endocrine-disrupting chemicals. Animal Behaviour 68, 665-676. 
Coon, J. S., Knudson, W., Clodfelter, K., Lu, B., Weinstein, R. S., 1991. Solutol HS 15, nontoxic polyxyethylene esters of 12-hydroxystearic acid, reverses multidrug resistance. Cancer Research 51, 897-902.

Cowles, T. J., 1983. Effects of exposure to sublethal concentrations of crude oil on the copepod Centropages hamatus II. Activity patterns. Marine Biology 78, 53-57.

Devreker, D., Souissi, S., Molinero, J. C., Nkubito, F., 2008. Trade-offs of the copepod Eurytemora affinis in mega-tidal estuaries: insights from high frequency sampling in the Seine estuary. Journal of Plankton Research 30, 1329-1342.

Devreker, D., Souissi, S., Winkler, G., Forget-Leray, J., Leboulanger, F., 2009. Effects of salinity, temperature and individual variability on the reproduction of Eurytemora affinis (Copepoda; Calanoida) from the Seine estuary: A laboratory study. Journal of Experimental Marine Biology and Ecology 368, 113-123.

Dodson, S. I., Hanazato, T., Gorski, P. R., 1995. Behavioral responses of Daphnia pulex exposed to carbaryl and Chaoborus kairomone. Environmental Toxicology and Chemistry 14, 43-50.

Dracos, T. (Ed.), 1996. Three-dimensional velocity and vorticity measuring and image analysis techniques: lecture notes from the short course held in Zürich, Switzerland, 3-6 September 1996. Kluwer Academic Publishers (Dordrecht and Boston).

Duquesne, S., Küster, E., 2010. Biochemical, metabolic, and behavioural responses and recovery of Daphnia magna after exposure to an organophosphate. Ecotoxicology and Environmental Safety 73, 353-359.

Escher, B. I., Hermens, J. L. M., 2002. Modes of action in ecotoxicology: their role in body burdens, species sensitivity, QSARs, and mixture effects. Environmental Science and Technology 36, 4201-4217.

Fernandes, M. B., Sicre, M. A., Boireau, A., Tronczynski, J., 1997. Polyaromatic hydrocarbon (PAH) distributions in the Seine River and its Estuary. Marine Pollution Bulletin 34, 857-867. 
Fisher, N. S., Hook, S. E., 2002. Toxicology tests with aquatic animals need to consider the trophic transfer of metals. Toxicology 181-182, 531-536.

Forget-Leray, J., Landriau, I., Minier, C., Leboulenger, F., 2005. Impact of endocrine toxicants on survival, development, and reproduction of the estuarine copepod $\mathrm{Eu}$ rytemora affinis (Poppe). Ecotoxicology and Environmental Safety 60, 288-294.

Garaventa, F., Gambardella, C., Fino, A. D., Pittore, M., Faimali, M., 2010. Swimming speed alteration of Artemia sp. and Brachionus plicatilis as a sub-lethal behavioural end-point for ecotoxicological surveys. Ecotoxicology 19, 512-519.

Garrido, S., Cruz, J., Santos, A. M. P., Ré, P., Saiz, E., 2013. Effects of temperature, food type and food concentration on the grazing of the calanoid copepod Centropages chierchiae. Journal of Plankton Research 35, 843-854.

Gonzalez, C. R. M., Bradley, B. P., 1994. Salinity stress proteins in Eurytemora affinis. Hydrobiologia 292-293, 461-468.

Guo, F., Wang, L., Wang, W. X., 2012. Acute and chronic toxicity of polychlorinated biphenyl 126 to Tigriopus japonicus: effects on survival, growth, reproduction, and intrinsic rate of population growth. Environmental Toxicology and Chemistry 31, 639-645.

Henry, M., Béguin, M., Requier, F., Rollin, O., Odoux, J. F., Aupinel, P., Aptel, J., Tchamitchian, S., Decourtye, A., 2012. A common pesticide decreases foraging success and survival in honey bees. Science $336,348-350$.

Heurtault, B., Saulnier, P., Pech, B., Proust, J. E., Benoit, J. P., 2002. A novel phase inversion-based process for the preparation of lipid nanocarriers. Pharmaceutical Research 19, 875-880.

Hutchinson, T. H., Shillabeer, N., Winter, M. J., Pickford, D. B., 2006. Acute and chronic effects of carrier solvents in aquatic organisms: A critical review. Aquatic Toxicology 76, 69-92. 
771 Jarvis, T. A., Miller, R. J., Lenihan, H. S., Bielmyer, G. K., 2013. Toxicity of ZnO

772 nanoparticles to the copepod Acartia tonsa, exposed through a phytoplankton diet. Environmental Toxicology and Chemistry 32, 1264-1269.

Jiang, H., Kiørboe, T., 2011. The fluid dynamics of swimming by jumping in copepods. Journal of the Royal Society Interface 8, 1090-1103.

Jiang, H., Meneveau, C., Osborn, T. R., 2002a. The flow field around a freely swimming copepod in steady motion. Part II: Numerical simulation. Journal of Plankton Research 24, 191-213.

Jiang, H., Osborn, T. R., Meneveau, C., 2002b. Chemoreception and the deformation of the active space in freely swimming copepods: a numerical study. Journal of Plankton Research 24, 495-510.

Kelley, D. H., Ouellette, N. T., 2013. Emergent dynamics of laboratory insect swarms. Scientific Reports 3, 1073.

Kienle, C., Gerhardt, A., 2008. Behavior of Corophium volutator (Crustacea, Amphipoda) exposed to the water-accommodated fraction of oil in water and sediment. Environmental Toxicology and Chemistry 27, 599-604.

Kiørboe, T., 2008. Optimal swimming strategies in mate-searching pelagic copepods. Oecologia 155, 179-192.

Kiørboe, T., 2011. What makes pelagic copepods so successful? Journal of Plankton Research 33, 677-685.

Kiørboe, T., Jiang, H., 2013. To eat and not be eaten: optimal foraging behaviour in suspension feeding copepods. Journal of the Royal Society Interface 10, 20120693.

Kiørboe, T., Jiang, H., Colin, S. P., 2010. Danger of zooplankton feeding: the fluid signal generated by ambush-feeding copepods. Proceedings of the Royal Society B 277, 3229-3237. 
Kiørboe, T., Jiang, H., Gonçalves, R. J., Nielsen, L. T., Wadhwa, N., 2014. Flow disturbances generated by feeding and swimming zooplankton. Proceedings of the National Academy of Sciences of the USA 111, 11738-11743.

Kirkpatrick, A., Gerhardt, A., Dick, J. T. A., McKenna, M., Berges, J. A., 2006. Use of the multispecies freshwater biomonitor to assess behavioral changes of Corophium volutator (Pallas, 1766) (Crustacea, Amphipoda) in response to toxicant exposure in sediment. Ecotoxicology and Environmental Safety 64, 298-303.

Koelmans, A. A., 2014. Limited reversibility of bioconcentration of hydrophobic organic chemicals in phytoplankton. Environmental Science and Technology 48, $7341-7348$.

Kwok, K. W. H., Souissi, S., Dur, G., Won, E. J., Lee, J. S., 2015. Copepods as references species in estuarine and marine waters. In: Amiard-Triquet, C., Amiard, J. C., Mouneyrac, C. (Eds.), Aquatic Ecotoxicology: Advancing Tools for Dealing with Emerging Risks. Elsevier Academic Press, pp. 281-308.

Lauritano, C., Procaccini, G., Ianora, A., 2012. Gene expression patterns and stress response in marine copepods. Marine Environmental Research 76, 22-31.

Lee, K. W., Raisuddin, S., Hwang, D. S., Park, H. G., Lee, J. S., 2007. Acute toxicities of trace metals and common xenobiotics to the marine copepod Tigriopus japonicus: Evaluation of its use as a benchmark species for routine ecotoxicology tests in Western Pacific coastal regions. Environmental Toxicology 22, 532-538.

Lesueur, T., Boulangé-Lecomte, C., Restoux, G., Deloffre, J., Xuereb, B., Menach, K. L., Budzinski, H., Petrucciani, N., Marie, S., Petit, F., Forget-Leray, J., 2015. Toxicity of sediment-bound pollutants in the Seine estuary, France, using a Eurytemora affinis larval bioassay. Ecotoxicology and Environmental Safety 113, 169-175.

Lesueur, T., Boulangé-Lecomte, C., Xuereb, B., Budzinski, H., Cachot, J., Vicquelin, L., Giusti-Petrucciani, N., Marie, S., Petit, F., Forget-Leray, J., 2013. Development of a larval bioassay using the calanoid copepod, Eurytemora affinis to assess the 
toxicity of sediment-bound pollutants. Ecotoxicology and Environmental Safety 94, 60-66.

Liberzon, A., Lüthi, B., Holzner, M., Ott, S., Berg, J., Mann, J., 2012. On the structure of acceleration in turbulence. Physica D 241, 208-215.

Lopes, I., Baird, D. J., Ribeiro, R., 2004. Avoidance of copper contamination by field populations of Daphnia longispina. Environmental Toxicology and Chemistry 23, $1702-1708$.

Lotufo, G. R., 1998. Bioaccumulation of sediment-associated fluoranthene in benthic copepods: uptake, elimination and biotransformation. Aquatic Toxicology 44, 1-15.

Lovern, S. B., Strickler, J. R., Klaper, R., 2007. Behavioral and physiological changes in Daphnia magna when exposed to nanoparticle suspensions (titanium dioxide, nano- $\mathrm{C}_{60}$, and $\mathrm{C}_{60} \mathrm{HxC}_{70} \mathrm{Hx}$. Environmental Science and Technology 41, 44654470.

Lynn, S. G., Price, D. J., Birge, W. J., Kilham, S. S., 2007. Effect of nutrient availability on the uptake of PCB congener 2,2',6,6'-tetrachlorobiphenyl by a diatom (Stephanodiscus minutulus) and transfer to a zooplankton (Daphnia pulicaria). Aquatic Toxicology 83, 24-32.

Maas, H. G., Gruen, A., Papantoniou, D., 1993. Particle tracking velocimetry in threedimensional flows. Part I. Photogrammetric determination of particle coordinates. Experiments in Fluids 15, 133-146.

Magnusson, K., Magnusson, M., Östberg, P., Granberg, M., Tiselius, P., 2007. Bioaccumulation of ${ }^{14} \mathrm{C}$-PCB 101 and ${ }^{14} \mathrm{C}$-PBDE 99 in the marine planktonic copepod Calanus finmarchicus under different food regimes. Marine Environmental Research $63,67-81$.

Malik, N. A., Dracos, T., Papantoniou, D. A., 1993. Particle tracking velocimetry in three-dimensional flows. Part II. Particle tracking. Experiments in Fluids 15, 279294. 
McFarland, V. A., Clarke, J. U., 1989. Environmental occurrence, abundance, and potential toxicity of polychlorinated biphenyl congeners: considerations for a congener-specific analysis. Environmental Health Perspectives 81, 225-239.

Medina, M., Barata, C., Telfer, T., Baird, D. J., 2002. Age- and sex-related variation in sensitivity to the pyrethroid cypermethrin in the marine copepod Acartia tonsa Dana. Archives of Environmental Contamination and Toxicology 42, 17-22.

Melvin, S., Wilson, S. P., 2013. The utility of behavioral studies for aquatic toxicology testing: A meta-analysis. Chemosphere 93, 2217-2223.

Michalec, F. G., Holzner, M., Hwang, J. S., Souissi, S., 2012. Three dimensional observation of salinity-induced changes in the swimming behavior of the estuarine calanoid copepod Pseudodiaptomus annandalei. Journal of Experimental Marine Biology and Ecology 438, 24-31.

Michalec, F. G., Holzner, M., Menu, D., Hwang, J. S., Souissi, S., 2013a. Behavioral responses of the estuarine calanoid copepod Eurytemora affinis to sub-lethal concentrations of waterborne pollutants. Aquatic Toxicology 138-139, 129-138.

Michalec, F. G., Kâ, S., Holzner, M., Souissi, S., Ianora, A., Hwang, J. S., $2013 b$. Changes in the swimming behavior of Pseudodiaptomus annandalei (Copepoda, Calanoida) adults exposed to the diatom toxin 2-trans, 4-trans decadienal. Harmful Algae 30, 56-64.

Michalec, F. G., Souissi, S., Holzner, M., 2015. Turbulence triggers vigorous swimming but hinders motion strategy in planktonic copepods. Journal of the Royal Society Interface 12, 20150158.

Miljeteig, C., Olsen, A. J., Nordtug, T., Altin, D., Jenssen, B. M., 2013. Sublethal exposure to crude oil enhances positive phototaxis in the calanoid copepod Calanus finmarchicus. Environmental Science and Technology 47, 14426-14433.

Moison, M., Schmitt, F. G., Souissi, S., 2012. Effect of temperature on Temora longicornis swimming behaviour: illustration of seasonal effects in a temperate ecosystem. Aquatic Biology 16, 149-162. 
Raisuddin, S., Kwok, K. W. H., Leung, K. M. Y., Schlenk, D., Lee, J. S., 2007. The copepod Tigriopus: A promising marine model organism for ecotoxicology and environmental genomics. Aquatic Toxicology 83, 161-173.

Ren, Z., Li, Z., Ma, M., Wang, Z., Fu, R., 2009. Behavioral responses of Daphnia magna to stresses of chemicals with different toxic characteristics. Bulletin of Environmental Contamination and Toxicology 82, 310-316.

Ren, Z., Zha, J., Ma, M., Wang, Z., Gerhardt, A., 2007. The early warning of aquatic organophosphorus pesticide contamination by on-line monitoring behavioral changes of Daphnia magna. Environmental Monitoring and Assessment 134, $373-$ 383.

Rozon-Ramilo, L. D., Dubé, M. G., Squires, A. J., Niyogi, S., 2011. Examining waterborne and dietborne routes of exposure and their contribution to biological response patterns in fathead minnow (Pimephales promelas). Aquatic Toxicology 105, 466481.

Russom, C. L., Bradbury, S. P., Broderius, S. J., Hammermeister, D. E., Drummond, R. A., 1997. Predicting modes of toxic action from chemical structure: acute toxicity in the fathead minnow (Pimephales promelas). Environmental Toxicology and Chemistry 16, 948-967.

Sabia, L., Uttieri, M., Schmitt, F. G., Zagami, G., Zambianchi, E., Souissi, S., 2014. Pseudodiaptomus marinus Sato, 1913, a new invasive copepod in Lake Faro (Sicily): observations on the swimming behaviour and the sex-dependent responses to food. Zoological Studies 53, 49.

Saha, D., Soos, M., Lüthi, B., Holzner, M., Liberzon, A., Babler, M. U., Kinzelbach, W., 2014. Experimental characterization of breakage rate of colloidal aggregates in axisymmetric extensional flow. Langmuir 30, 14385-14395.

Saiz, E., 1994. Observations of the free-swimming behavior of Acartia tonsa: effects of food concentration and turbulent water motion. Limnology and Oceanography 39 , 1566-1578. 
Saiz, E., Movilla, J., Yebra, L., Barata, C., Calbet, A., 2009. Lethal and sublethal effects of naphthalene and 1,2-dimethylnaphthalene on naupliar and adult stages of the marine cyclopoid copepod Oithona davisae. Environmental Pollution 157, 12191226.

Sokolova, I. M., Frederich, M., Bagwe, R., Lanning, G., Sukhotin, A. A., 2012. Energy homeostasis as an integrative tool for assessing limits of environmental stress tolerance in aquatic invertebrates. Marine Environmental Research 79, 1-15.

Sornom, P., Gismondi, E., Vellinger, C., Devin, S., Férard, J. F., Beisel, J. N., 2012. Effects of sublethal cadmium exposure on antipredator behavioural and antitoxic responses in the invasive amphipod Dikerogammarus villosus. PLoS ONE 7, e42435.

Souissi, A., Souissi, S., Hwang, J. S., 2013. The effect of epibiont ciliates on the behavior and mating success of the copepod Eurytemora affinis. Journal of Experimental Marine Biology and Ecology 445, 38-43.

Souissi, S., Michalec, F. G., Dur, G., Mahjoub, M. S., Schmitt, F. G., Hwang, J. S., 2010. How does salinity influence the swimming speed of the estuarine calanoid copepod Eurytemora affinis?: Reply. Journal of Plankton Research 32, 1227-1229.

Stancheva, S., Souissi, A., Ibrahim, A., Barras, A., Spriet, C., Souissi, S., Boukherroub, R., 2015. Lipid nanocapsules as a new delivery system in copepods: Toxicity studies and optical imaging. Colloids and Surfaces B: Biointerfaces 135, 441-447.

Steinke, M., Stefels, J., Stamhuis, E., 2004. Dimethyl sulfide triggers search behavior in copepods. Limnology and Oceanography 23, 1702-1708.

Sullivan, B. K., Buskey, E., Miller, D. C., Ritacco, P. J., 1983. Effects of copper and cadmium on growth, swimming and predator avoidance in Eurytemora affinis (Copepoda). Marine Biology 77, 229-306.

Tackx, M. L. M., Herman, P. J. M., Gasparini, S., Irigoien, X., Billiones, R., Daro, M. H., 2003. Selective feeding of Eurytemora affinis (Copepoda, Calanoida) in temperate estuaries: model and field observations. Estuarine, Coastal and Shelf Science $56,305-311$. 
Taylor, R. L., Caldwell, G. S., Dunstan, H. J., Bentley, M. G., 2007. Short-term impacts of polyunsaturated aldehyde-producing diatoms on the harpacticoid copepod, Tisbe holothuriae. Journal of Experimental Marine Biology and Ecology 341, 60-69.

van Duren, L. A., Videler, J. J., 1995. Swimming behaviour of developmental stages of the calanoid copepod Temora longicornis at different food concentrations. Marine Ecology Progress Series 126, 153-161.

van Wezel, A. P., Opperhuizen, A., 1995. Narcosis due to environmental pollutants in aquatic organisms: residue-based toxicity, mechanisms, and membrane burdens. Critical Reviews in Toxicology 25, 255-279.

Visser, A. W., 2007. Motility of zooplankton: fitness, foraging and predation. Journal of Plankton Research 29, 447-461.

Visser, A. W., Kiørboe, T., 2006. Plankton motility patterns and encounter rates. Oecologia 148, 538-546.

Vonarbourg, A., Passirani, C., Desigaux, L., Allard, E., Saulnier, P., Lambert, O., Benoit, J. P., Pitard, B., 2009. The encapsulation of DNA molecules within biomimetic lipid nanocapsules. Biomaterials 30, 3197-3204.

Wang, W. X., Dei, R. C., 2001. Effects of major nutrient additions on metal uptake in phytoplankton. Environmental Pollution 111, 233-240.

Wang, X., Wang, W. X., 2005. Uptake, absorption efficiency and elimination of DDT in marine phytoplankton, copepods and fish. Environmental Pollution 136, 453-464.

Ward, A. J. W., Duff, A. J., Horsfall, J. S., Currie, S., 2008. Scents and scents-ability: pollution disrupts chemical social recognition and shoaling in fish. Proceedings of the Royal Society B 274, 101-105.

Willneff, J., Gruen, A., February 2002. A new spatio-temporal matching algorithm for 3D-particle tracking velocimetry. In: Proceedings of the 9th International Symposium on Transport Phenomena and Dynamics of Rotating Machinery. Honolulu, HI, USA. 
Wolf, M., Lüthi, B., Holzner, M., Krug, D., Kinzelbach, W., Tsinober, A., 2012. Investigations on the local entrainment velocity in a turbulent jet. Physics of Fluids 24, 105110.

Xu, Y., Wang, W. X., Hsieh, D. P. H., 2001. Influences of metal concentration in phytoplankton and seawater on metal assimilation and elimination in marine copepods. Environmental Toxicology and Chemistry 20, 1067-1077.

Xuereb, B., Forget-Leray, J., Souissi, S., Glippa, O., Devreker, D., Lesueur, T., Marie, S., Danger, J. M., Boulangé-Lecomte, C., 2012. Molecular characterization and mRNA expression of grp 78 and $h s p 90 A$ in the estuarine copepod Eurytemora affinis. Cell Stress and Chaperones 17, 457-472.

Zala, S. M., Penn, D. J., 2004. Abnormal behaviours induced by chemical pollution: a review of the evidence and new challenges. Animal Behaviour 68, 649-664.

Zein, M. A., McElmurry, S. P., Kashian, D. R., Savolainen, P. T., Pitts, D. V., 2015. Toxic effects of combined stressors on Daphnia pullex: interactions between diazinon, 4-nonylphenol, and wastewater effluent. Environmental Toxicology and Chemistry $34,1145-1153$. 
Table 1: Number of three-dimensional coordinates for the different experimental conditions.

Table 2: Mean swimming velocity of $E$. affinis males and females for the different experimental conditions. The mean velocity was obtained by averaging instantaneous velocity magnitudes $u=\left(u_{x}^{2}+u_{y}{ }^{2}+u_{z}{ }^{2}\right)^{0.5}$

\begin{tabular}{|c|c|c|c|c|c|}
\hline & & $\mathrm{CON}$ & EMP & PAH & PCB \\
\hline \multirow{3}{*}{$\frac{\tilde{d}}{\sum \pi}$} & 00 & 3.4 & 3.7 & 4.0 & 4.8 \\
\hline & 03 & 3.4 & 4.5 & 4.0 & 4.7 \\
\hline & 24 & 3.4 & 4.1 & 3.4 & 3.8 \\
\hline \multirow{3}{*}{$\frac{\mathscr{d}}{\widetilde{Z}}$} & 00 & 2.9 & 3.0 & 3.0 & 4.2 \\
\hline & 03 & 2.9 & 3.7 & 3.2 & 4.3 \\
\hline & 24 & 2.8 & 3.6 & 3.2 & 3.6 \\
\hline
\end{tabular}

Table 3: Three-dimensional box-counting dimension (mean $\pm \mathrm{std}$ ) of $E$. affinis trajectories for the different experimental conditions.

\begin{tabular}{|c|c|c|c|c|c|}
\hline & & $\mathrm{CON}$ & EMP & PAH & PCB \\
\hline \multirow{3}{*}{ 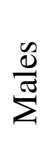 } & 00 & $1.24 \pm 0.08$ & $1.23 \pm 0.08$ & $1.25 \pm 0.09$ & $1.24 \pm 0.10$ \\
\hline & 03 & $1.25 \pm 0.09$ & $1.24 \pm 0.10$ & $1.24 \pm 0.09$ & $1.24 \pm 0.11$ \\
\hline & 24 & $1.23 \pm 0.08$ & $1.22 \pm 0.10$ & $1.24 \pm 0.09$ & $1.24 \pm 0.11$ \\
\hline \multirow{3}{*}{ 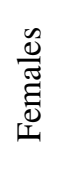 } & 00 & $1.41 \pm 0.18$ & $1.36 \pm 0.13$ & $1.32 \pm 0.12$ & $1.35 \pm 0.16$ \\
\hline & 03 & $1.40 \pm 0.17$ & $1.35 \pm 0.12$ & $1.34 \pm 0.13$ & $1.36 \pm 0.16$ \\
\hline & 24 & $1.38 \pm 0.15$ & $1.30 \pm 0.11$ & $1.33 \pm 0.13$ & $1.35 \pm 0.15$ \\
\hline
\end{tabular}




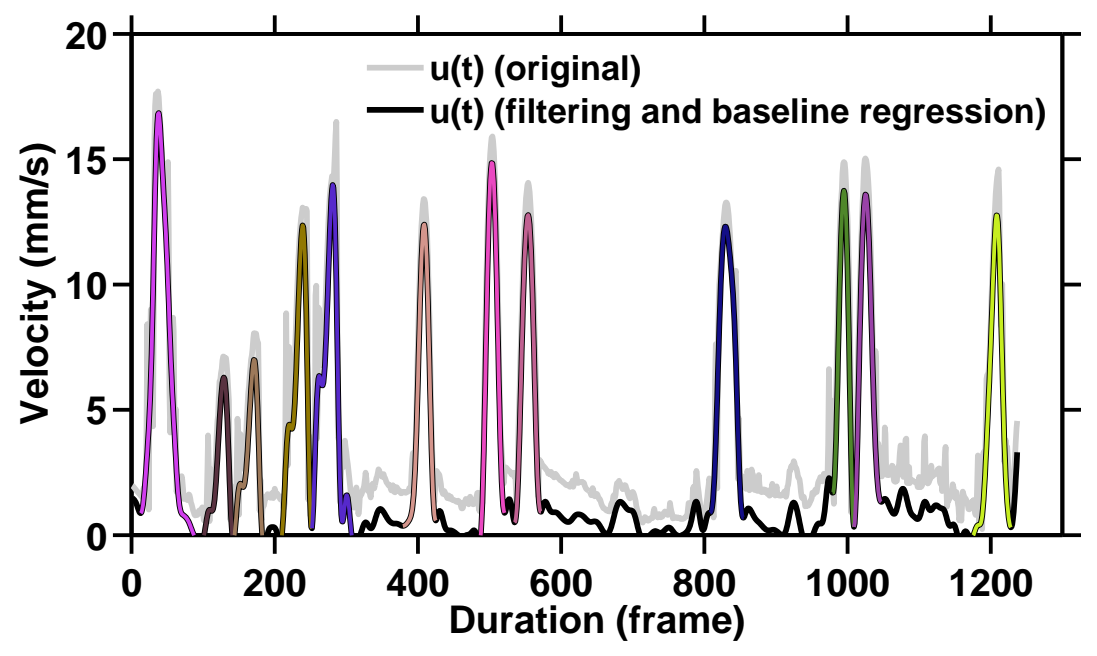

Figure 1: Illustration of the jump detection procedure. The original velocity time series (grey) is filtered to remove high frequency fluctuations caused by inaccuracies in the reconstruction of coordinates. After baseline regression, jumps are detected using a wavelet-based peak detection method. The transformed velocity time series is shown in black, and jumps are shown in different colours. [single-column fitting image] 

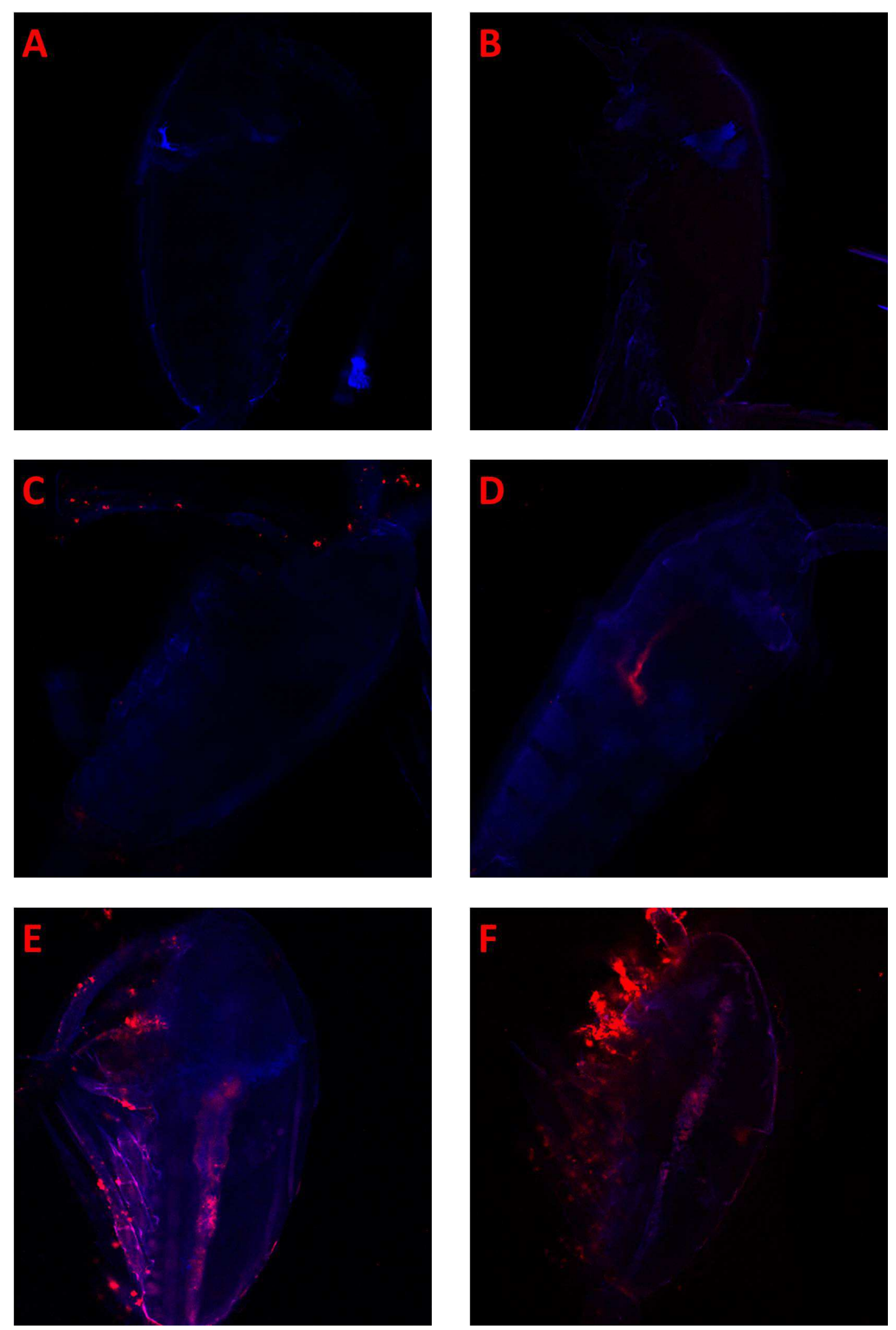

Figure 2: Microscope images of the studied copepods showing fluorescence (nanocapsules loaded with DiI at $0.1 \%$ and PCB 153 at $1 \%$ ) in control organisms (A), after 30 min of exposure (B), at t $=3 \mathrm{~h}(\mathrm{C}$ and D) and at $\mathrm{t}=24 \mathrm{~h}(\mathrm{E}$ and $\mathrm{F})$. The blue colour is due to the auto-fluorescence of the exoskeleton while the red colour comes from the fluorescence of the dye. The gut congegtration of capsules and their adhesion to the cuticule and appendages increase drastically between $\mathrm{t}=3 \mathrm{~h}$ and $\mathrm{t}=24 \mathrm{~h}$. Nanocapsules contained both DiI and PCB to ensure that even toxicant-loaded carriers were ingested by the copepods. [1.5-column fitting image] 

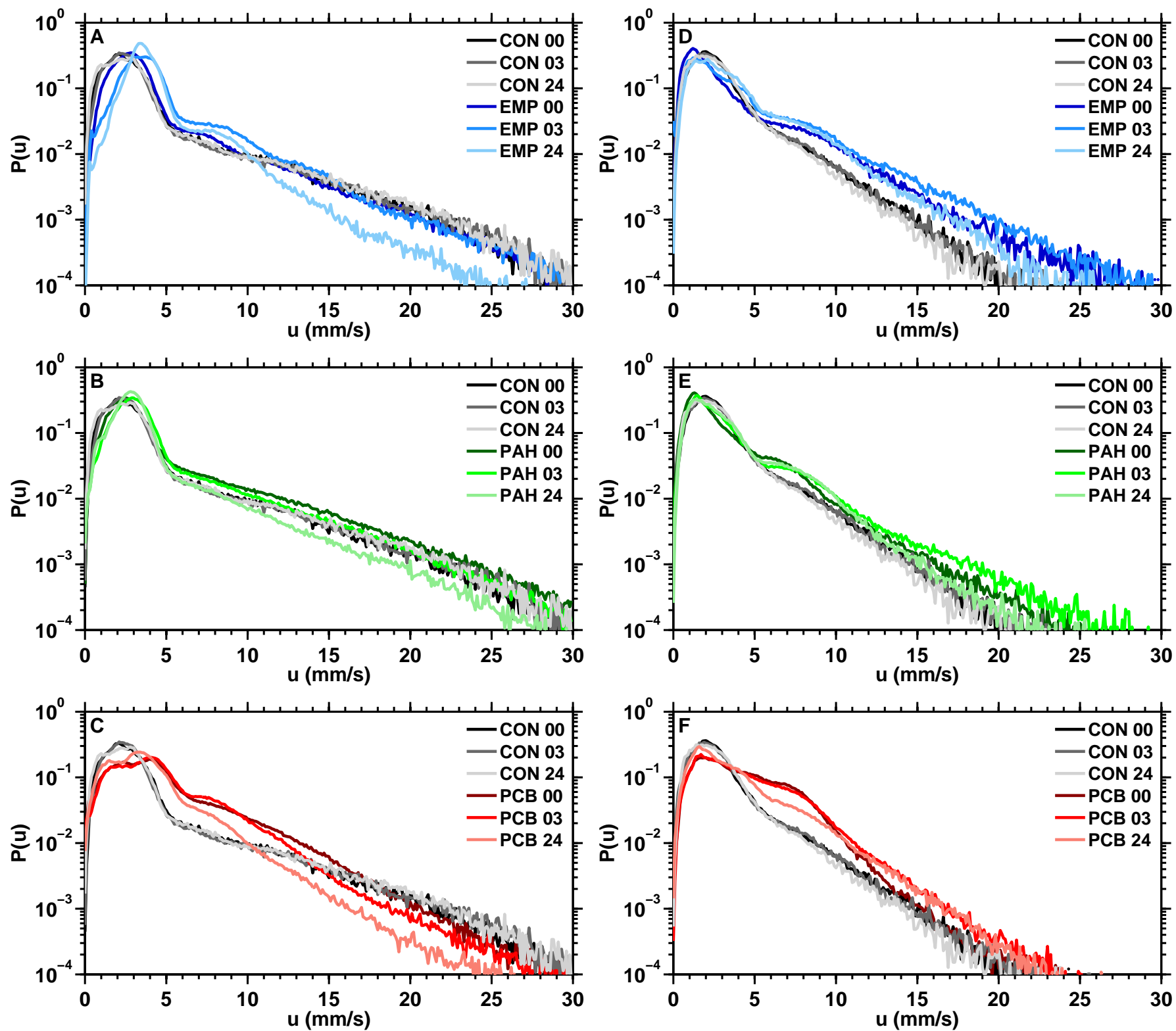

Figure 3: Probability density functions of the magnitude of the velocity for E. affinis males (A, B and C) and females (D, E and F) exposed to empty nanocapsules (A, D), to nanocapsules filled with PAHs (B, E) and to nanocapsules filled with PCB 153 (C, F). Control curves are shown in each figure for comparison. Lighter colours indicate longer exposures. [2-column fitting image] 

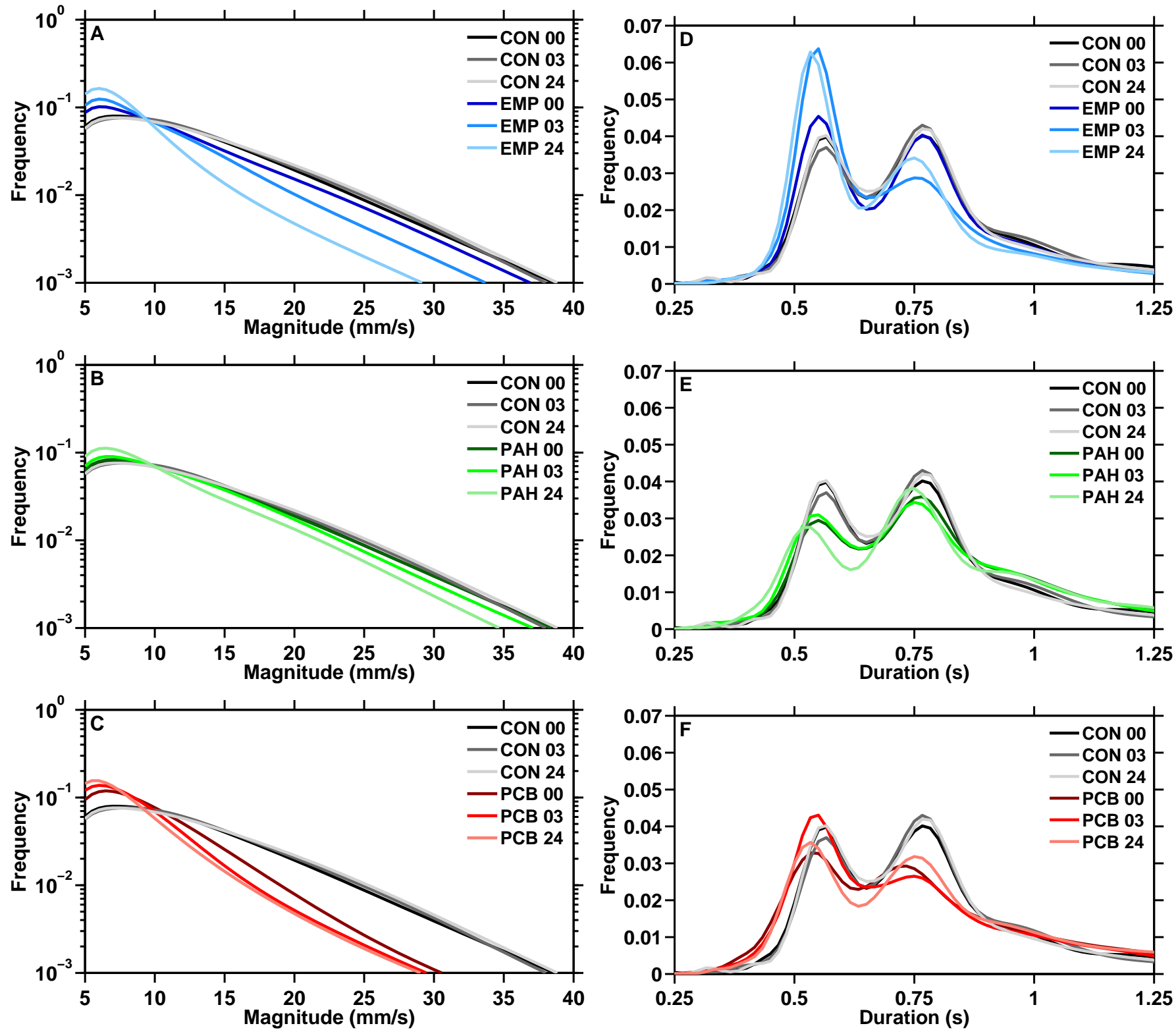

Figure 4: Probability density functions of the magnitude (A, B and C) and duration (D, E and F) of jumps for E. affinis males exposed to empty nanocapsules (A, D), to nanocapsules filled with PAHs (B, E) and to nanocapsules filled with PCB 153 (C, F). Control curves are shown in each figure for comparison. Lighter colours indicate longer exposures. All curves are kernel density smoothing estimates. [2-column fitting image] 

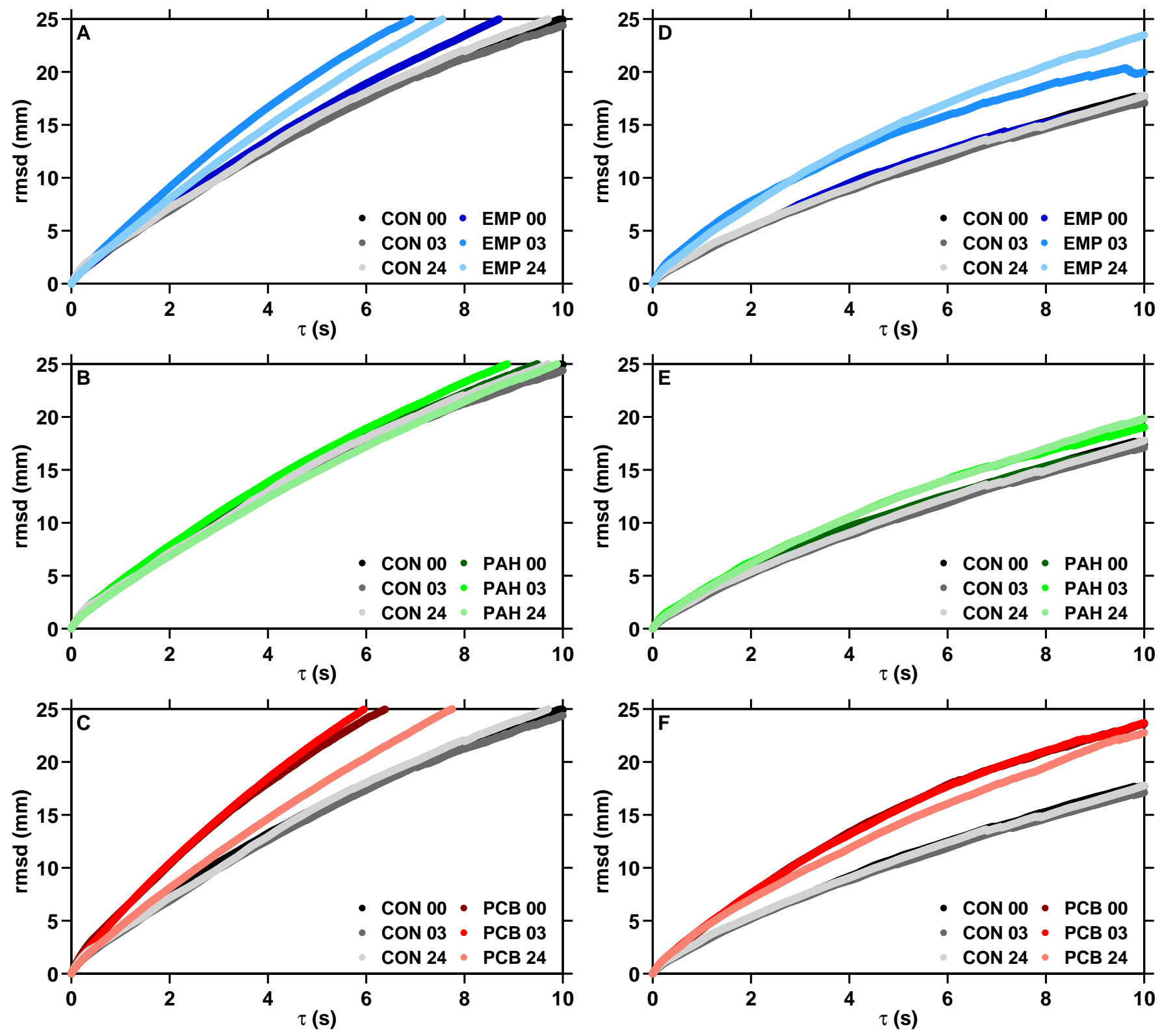

Figure 5: Root mean square displacement for E. affinis males (A, B and C) and females (D, E and F) exposed to empty nanocapsules (A, D), to nanocapsules filled with PAHs (B, E) and to nanocapsules filled with PCB 153 (C, F). Control curves are shown in each figure for comparison. Lighter colours indicate longer exposures. [2-column fitting image] 